\title{
Identifkasi Senyawa Aktif Kulit Batang Ampupu (Eucalyptus alba Reinw. Ex. Blume) dalam Menghambat Pertumbuhan Jamur Fusarium moniliforme
}

Bernadina Metboki ${ }^{\mathrm{a}}$

${ }^{a}$ FakultasPertanian, Universitas Timor, Kefamenanu, TTU - NTT, Indonesia.

\section{Article Info}

\section{Articlehistory:}

Received 20 November 2017

Received in revised form 10 Desember 2017

Accepted 3 Januari 2018

\section{Keywords:}

Aktivitas Anti Jamur

Ampupu

Fusarium moniliforme

\section{Abstrak}

Produksi jagung yang rendah di Indonesia disebabkan oleh banyak faktor salah satunya adalah penyakit yang disebabkan oleh jamur. Pengendalian jamur dengan menggunakan bahan kimia sangat berbahaya bagi kesehatan. Oleh karena itu, diperlukan usaha pengembangan fungisida nabati yang ramah lingkungan, misalnya dengan menggunakan ekstrak kulit batang ampupu. Tujuan penelitian untuk mengetahui efek anti jamur dari ekstrak kulit batang ampupu terhadap pertumbuhan jamur Fusarium sp. yangmenyebabkan busuk tongkoljagung. Pengujian hambatan pertumbuhan Fusarium sp. oleh ekstrak kulit batang ampupu dilakukan di laboratorium dengan metode sumur difusi pada media PDA. Ekstrak dengan konsentrasi 1,5\%, 3,0\%, 4,5\% di masukkan dalam sumur difusi pada setiap petri. Identifikasi senyawa aktif menggunakan Kromatografi Gas-Spektroskopi Massa.Hasil penelitian menunjukkan bahwa secara in vitro ekstrak kasar kulit batang ampupu dengan konsentrasi 1,5\%,3,0\%, dan 4,5\% mampu menghambat pertumbuhan jamur Fusarium moniliforme dengan diameter zona hambatan masing-masing adalah $0,18 \mathrm{~mm}, 1,85 \mathrm{~mm}, 2,01 \mathrm{~mm}$. peningkatan konsentrasi ekstrak yang diberikan menyebabkan zona hambatan yang terbentuk lebih besar. Sebelas senyawa dalam ekstrak methanol kulit batang ampupu diketahui berpotensi sebagai anti jamur yaitu Ethylbenzene, o-Xylene, ALPHA.-PINENE,DELTA.3-Carene, Azulene(CAS)Cyclopentacycloheptene, Tetradecane(CAS)nTetradecane, 2,6-Diisopropylnaphthalene, 7,9-Di-tert-butyl-1-oxaspiro(4,5)deca-6,9-dien, Hexadecanamide, 9-Octadecenamide, (Z)(CAS)OLEOAMIDE, 1,2-Benzenedicarboxylicacid,mono(2-ethylhexyl). @2018 dipublikasikan oleh Savana Cendana.

\section{Pendahuluan}

Jagung merupakan salah satu sumber karbohidrat yang cukup potensial. Namun kebutuhan jagung untuk pangan maupun pakan dan pakan baik kualitas maupun kuantitas belum terpenuhi sehingga masih impor dari Negara lain (Passaribu, 1995). Produksi jagung di Indonesia tahun 2013 adalah 18,51 juta ton, sedangkan kebutuhan jagung untuk pangan, pakan dan industry mencapai 27,14 juta ton (BPS, 2014). Rendahnya produksi jagung Indonesia disebabkan oleh banyak faktor salah satunya adalah faktor biologis. Penyakit tanaman jagung khususnya yang diakibatkan karena jamur yang menyebabkan busuk tongkol jagung, berkontribusi secara signifikan terhadap kerugian hasil pertanian (Pakki, 2006; Baco dan Tandiabang, 1998). Fusarium sp. merupakan jamuryang menyebabkan busuk tongkol Fusariumpada jagung (Bahri, 2001)

Penggunaan fungisida kimia dapat memberikan efek berbahaya bagi manusia dan lingkungan (Goldman, 2008). Sehingga perlu dilakukan eksploras bahan alam sebagai fungisida nabatiPengembangan teknologi untuk menghasilkan fungisida nabati yang lebih efektif untuk bidang pertanian sangat diperlukan. Pengembangan fungisida nabati, dengan bahan aktif berupa ekstrak tumbuhan untuk mengendalikan penyakit jamur dan bakteri, merupakan salah satu upaya untuk mengurangi penggunaan fungisida sintetik dan mengurang dampak negatif yang ditimbulkannya, baik terhadap kesehatan manusia maupun terhadap lingkungan (Yulia, 2006; Suprapta, 2014). Penggunaan Ampupu sebagai fungisida nabati diharapkan mampu mengurangi pencemaran terhadap manusia dan lingkungan.

\section{Metod}

Kulit batang tanaman Ampupu di peroleh dari hutan rakyat Kabupaten Timor Tengah Utara. Sampel dikumpulkan, kemudian dipilih dan dikeringanginkan selama 4-6 hari. Kulit batang yang sudah kering angin lalu diblender hingga menjadi serbuk. Serbuk kulit batang tanaman Ampupu dibungkus lalu disimpan di tempat kering dan tertutup rapat.

Pembuatan ekstrak kulit batang ampupu meliputi kulit batang tanaman Ampupu diekstrak dengan menggunakan metode maserasi yaitu $100 \mathrm{~g}$ serbuk kulit batang Ampupu di rendam dalam satu liter methanol selama 72 jam (3 hari) pada suhu kamar. Setelah itu maserat di saring menggunakan kertas saring lalu hasil rendaman di evaporasi menggunakan rotary evaporator pada suhu $40^{\circ} \mathrm{C}$ untuk mendapatkan ekstrak kasar.

\subsection{Uji Aktivitas Antijamur kulit batang Ampupu}

Petri yang telah berisi $10 \mathrm{~mL}$ media PDA dan $200 \mu \mathrm{L}$ suspensi jamur dibiarkan memadat. Setelah padat dibuat sumur difusi masing-masing sebanyak 2 buah pada setiap petri dengan menggunakan cork borer. Setiap sumur difusi diisi dengan $20 \mu \mathrm{l}$ ekstrak kasar kulit batang tanaman ampupu. Zona hambatan yang terbentuk disekitar sumur difusi diukur diameternya.

\subsection{Partisi dan Identifikasi Fraksi aktif}

Pemisahan ekstrak fase Metanol dan fase Heksan: Kedua fase diuji daya hambatnya terhadap jamur pada media PDA dengan metode sumur difusi. Fase yang menimbulkan hambatan (mempunyai aktivitas fungisida) terhadap pertumbuhan jamur selanjutnya di fraksinasi menggunakan kromatografi kolom (Astitiet al., 2012)

Fraksinasi Komponen aktif dengan Kromatografi Lapis Tipis (KLT) dan Kromatografi Kolom (KK): Hasil uji ekstrak hasil partisi yang memiliki daya hambat tertinggi dianalisis senyawanya dengan melakukan uji KLT. Filtrat ditotolkan pada lempeng KLT (Silica gel plat Merck 60 F254) yang dikembangkan dengan campuran N-Heksan:Etil aseta:Metanol (5:1:1, v/v) Noda aktif divisualisasikan di bawah sinar UV $\lambda 254$ dan $\lambda 365 \mathrm{~nm}$ (Ali, 2009). Untuk memurnikan senyawa dilanjutkan dengan kromotografi kolom dengan menggunakan silica gel sebagai fase diam dan fase geraknya menggunakan pelarut campuran hasil pengembang pada KLT. Fraksi-fraksi hasil kromatografi kolom di lakukan KLT kedua dan fraksi yang memiliki nilai Rf yang sama digabung lalu diujikan pada jamur patogen.

Spot - spot pada plat KLT dibandingkan dengan menggunakan nilai satuan tertentu yaitu Retention factor (Rf). Nilai Rf adalah perbandingan jarak dari titik awal spot sehingga sejauh spot itu berada dibandingkan dengan jarak pelarut hingga mencapai titik tertinggi yang dihitung dari titik awal yang sama (titik spot awal sebelum pengembangan). Spot yang bergerak mencapai bagian atas plat kromatografi mempunyai nilai Rf yang lebih besar dibanding spot - spot yang bergerak hanya mencapai bagian tengah plat kromatografi. Karena spot biasanya cukup besar, maka pengukuran spot tersebut dilakukan mulai dari titik awa hingga titik tengah spot (Sastrohamidjojo, 1985). Rumus Rf adalah:

$$
\text { Retention factor }(\mathrm{Rf})=\frac{\mathrm{r} 1}{r 2}
$$

Keterangan :

r1: Jarak yang ditempuh substansi $(\mathrm{cm})$

r2: Jarak yang ditempuh fase gerak $(\mathrm{cm})$

\subsection{Uji Aktivitas antijamur hasil fraksinasi}

Semua fraksi yang diperoleh diuji aktivitasnya untuk menghambat pertumbuhan jamur Fusarium moniliforme. Pengamatan dilakukan dengan melihat zona hambatan dari masing-masing fraksi terhadap pertumbuhan jamur. Fraksi yang menunjukkan daya hambat tertinggi kemudian di analisis senyawa aktifnya menggunakan KG-SM

\subsection{Uji Fitokimia}

Uji fitokimia (Harborne, 1987) dengan menggunakan pereaksi golongan senyawa yang spesifik. Metode ini dilakukan pada fraksi yang menunjukkan sifat antijamur yang paling tinggi. Pereaksi yang digunakan adalah sebagai berikut:

a. Golongan senyawa alkaloid

Sedikit isolat ditambahkan beberapa tetes pereaksi Wagner, Reaksi positif jika terbentuk endapan coklat.

b. Golongan senyawa Flavonoid

Sedikit isolat ditambah tetes pereaksi $\mathrm{NaOH} 10 \%$. Reaksi positif jika terjadi perubahan warna yang spesifik

c. Golongan senyawa steroid dan triterpenoid

Sedikit isolat ditambah pereaksi Libermann-Burchard, jika terjadi perubahan warna hijau -biru menunjukkan positif steroid, dan jika terjadi perubahan warna merah-ungu menunjukkan positif triterpenoid.

d. Golongan polifenol

Sedikit isolat ditambah pereaksi $\mathrm{FeCl}_{3} 1 \%$. Reaksi positif jika terbentuk warna hijau kehitaman.

e. Golongan saponin

Mencampurkan sampel dengan air panas dan dikocok, adanya saponin ditandai dengan terbentuknya busa yang tahan lama pada permukaan cairan.

\subsection{Analisis Kromatografi Gas - Spektroskopi Massa (KG-SM)}

Cuplikan fraksi yang paling aktif dan relatif murni dianalisis dengan kromatografi gas - spektroskopi massa. Melalui kecocokan bobot molekul dan pola fragmentasi dari senyawa hasil isolasi dengan senyawa pada library pada system KG-SM, maka senyawa hasil isolasi dapat diketahui strukturnya.

\section{Hasil dan Pembahasan}

\subsection{Uji Daya Hambat Ekstrak Hasil Partisi}

Berdasarkan hasil partisi menggunakan metode counter current distribution dengan dua jenis pelarut yaitu heksan dan metanol menunjukkan bahwa ekstrak fraksi metanol dapat menghambat pertumbuhan $F$. moniliforme dengan diameter 
zona hmbatan sebesar $13,33 \mathrm{~mm}$, sedangkan ekstrak fase heksan tidak dapat menghambat pertumbuhan F. moniliforme (Gambar 1.).

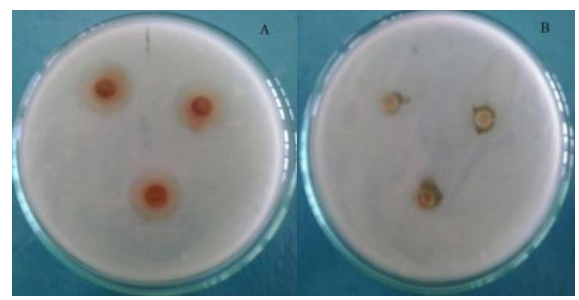

Gambar 1. Hasil uji ekstrak Ampupu hasil partisi

menggunakan (A) fase metanol dan (B) fase heksan

Hasil ini menunjukkann bahwa senyawa aktif pada ekstrak kulit batang Ampupu yang bersifat antijamur terhadap F. moniliforme pada fase metanol.

\subsection{Analisis senyawa ekstrak kulit batang ampupu dengan KLT}

Uji kromatografi lapis tipis terhadap ekstrak kulit batang ampupu menunjukkan dua (2) spot yang terbentuk pada plat KLT dengan menggunakan eluen campuran Heksan: Etil asetat: Metanol: 5:1:1. Sehingga dilakukan kromatografi kolom untuk memisahkan senyawa aktif tersebut. Pada proses kromatografi kolom didapatkan 54 botol eluat. Dari 54 eluat tersebut dicari nilai Rf yang sama sehingga didapatkan tiga fraksi seperti tercantum pada Tabel 1.

Tabel 1. Fraksinasi ekstrak kulit batang menggunakan kromatografi lapis tipis

\begin{tabular}{ccc}
\hline No & Fraksi & Nilai Rf \\
\hline 1 & I & 0,82 \\
2 & II & $0,77.0,85^{*}$ \\
3 & III & $0,68.0,35^{*}$ \\
\hline
\end{tabular}

Keterangan: Tanda $(*)$ menunjukkan bahwa terdapat dua spot yang memiliki nilai Rf yang berbeda.

Hasil KLT yang didapat kemudian masing-masing diujikan pada jamur $F$. moniliforme. Dari 3 fraksi tersebut, fraksi II yang menimbulkan daya hambat terbesar terhadap pertumbuhan $F$. moniliforme dengan zona hambat sebesar 14 mm sedangkan fraksi I dan fraksi III tdk terbentuk zona bening disekitar sumur difusi seperti yang tertera pada Gambar 2.

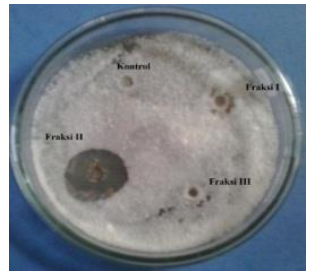

Gambar 2. Hasil uji fraksi hasil kromatografi Lapis Tipis

Fraksi II yang memiliki daya hambat terbesar terhadap pertumbuhan $F$. moniliforme selanjutnya dianalisis komponen senyawa aktif yang terkandung didalamnya dengan menggunakan Kromatografi Gas-Spektroskopi Massa (KGSM QP 2010S SHIMADZU).

Table 2. Uji Bioassay hasil fraksinasi KLT ekstrak kulit batang tanaman ampupu terhadap Fusarium moniliforme

\begin{tabular}{ccc}
\hline No & Fraksi & Diameter Zona Hambat $(\mathrm{mm})$ \\
\hline 1 & I & 0,00 \\
2 & II & 14,0 \\
3 & II & 0,00 \\
\hline
\end{tabular}

\subsection{Uji Fitokimia}

Hasil pengujian fitokimia ekstrak kulit batang Ampupu yang dilaksanakan di laboratorium Kimia Terapan, Program Pasacasarjana Universitas Udayana, menunjukkan bahwa ektrak kulit batang ampupu mengandung senyawa bioaktif triterpenoid/steroid, flavonoid, alkaloid, fenolat, dan tannin (Tabel 3.).

Tabel 3. Uji fitokimia Ekstrak Kulit batang ampupu (Eucalyptus alba Reinw. Ex. Blume)

\begin{tabular}{llc}
\hline \multicolumn{1}{c}{ Golongan } & \multicolumn{1}{c}{ Perubahan warna } & Keterangan \\
\hline $\begin{array}{l}\text { Triterpenoid/ } \\
\text { steroid }\end{array}$ & $\begin{array}{l}\text { Coklat menjadi coklat ungu } \\
\text { Coklat menjadi coklat ungu }\end{array}$ & + \\
\hline \multirow{2}{*}{ Flavonoid } & $\begin{array}{l}\text { Coklat menjadi hijau kekuningan } \\
\text { Coklat menjadi orange } \\
\text { Coklat menjadi orange }\end{array}$ & + \\
& $\begin{array}{l}\text { Terbentuk endapan coklat } \\
\text { Coklat menjadi biru kehitaman }\end{array}$ & + \\
Fenolat & $\begin{array}{l}\text { Coklat menjadi biru kehitaman } \\
\text { Terbentuk endapan putih }\end{array}$ & + \\
\hline Tanin & Tidak terbentuk busa yang stabil & - \\
\hline Saponin & \multicolumn{2}{c}{ Keterangan: (+):mengandung senyawa bioaktif; (-): tidak mengandung senyawa } \\
& bioaktif
\end{tabular}

\subsection{Analisis Kromatografi Gas - Spektroskopi Massa (KG-SM)}

Fraksi 2 hasil kolom kromatografi yang memberikan hambatan terbesar pada uji bioassay selanjutnya dianalisis menggunakan KG-SM yangmemperlihatkan 15 puncak. Masing - masing puncak diidentifikasi lebih lanjut dengan spektroskopi masa dimana setiap senyawa mempunyai pola fragmentasi masa yang spesifik (Gambar 3.). Identifikasi senyawa pada masing-masing puncak dilakukan dengan membandingkan spektrum masa masing-masing puncak dengan spektrum masa senyawa - senyawa yang telah diketahui dan terprogram dalam data base KG-SM, sehingga dapat diduga senyawa-senyawa penyusun fraksi aktif antijamur ekstrak kulit batang ampupu.

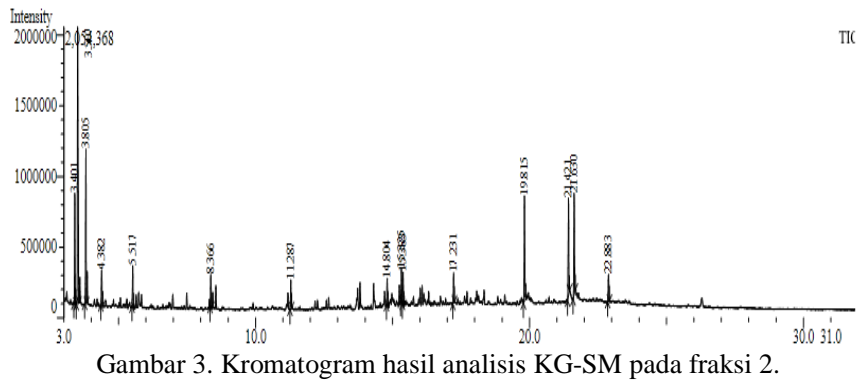

Identifikasi dilakukan dengan membandingkan spektrum massa masingmasing puncak dengan spektrum massa senyawa-senyawa yang telah diketahui dan terpogram dalam database KG-SM. Sehingga dapat diduga senyawasenyawa aktif penyusun fraksi kulit batang tanaman Ampuu.

Tabel 4. Senyawa-senyawa aktif sebagai fungisida nabatai yang teridentifikasi dalam ekstrak kulit batang Ampupu hasil analisis KG-SM

\begin{tabular}{|c|c|c|c|c|c|}
\hline No & Puncak & WR & $\mathrm{BM}$ & RM & $\begin{array}{c}\text { Senyawa aktif berdasarkan } \\
\text { data base SM }\end{array}$ \\
\hline 1 & Puncak 1 & 3,401 & 106 & $\mathrm{C}_{8} \mathrm{H}_{10}$ & Ethylbenzene \\
\hline 2 & Puncak 2 & 3,507 & 106 & $\mathrm{C}_{8} \mathrm{H}_{10}$ & o-Xylene \\
\hline 3 & Puncak 3 & 3,806 & 106 & $\mathrm{C}_{8} \mathrm{H}_{10}$ & o-Xylene \\
\hline 4 & Puncak 4 & 4,382 & 136 & $\mathrm{C}_{10} \mathrm{H}_{16}$ & ALPHA.-PINENE, (-)- \\
\hline 5 & Puncak 5 & 5,517 & 136 & $\mathrm{C}_{10} \mathrm{H}_{16}$ & DELTA.3-Carene \\
\hline 6 & Puncak 6 & 8,366 & 128 & $\mathrm{C}_{10} \mathrm{H}_{8}$ & $\begin{array}{l}\text { Azulene (CAS) } \\
\text { Cyclopentacycloheptene }\end{array}$ \\
\hline 7 & Puncak 7 & 11,286 & 198 & $\mathrm{C}_{14} \mathrm{H}_{30}$ & $\begin{array}{l}\text { Tetradecane (CAS) n- } \\
\text { Tetradecane }\end{array}$ \\
\hline 8 & Puncak 8 & 14,804 & 212 & $\mathrm{C}_{16} \mathrm{H}_{2} \mathrm{O}$ & 2,6-Diisopropylnaphthalene \\
\hline 9 & Puncak 9 & 15,324 & 212 & $\mathrm{C}_{16} \mathrm{H}_{2} \mathrm{O}$ & 2,6-Diisopropylnaphthalene \\
\hline 10 & Puncak 10 & 15,383 & 212 & $\mathrm{C}_{16} \mathrm{H}_{2} \mathrm{O}$ & 2,6-Diisopropylnaphthalene \\
\hline 11 & Puncak 11 & 17,232 & 276 & $\mathrm{C}_{17} \mathrm{H}_{24} \mathrm{O}_{3}$ & $\begin{array}{l}\text { 7,9-Di-tert-butyl-1- } \\
\text { oxaspiro(4,5)deca-6,9-dien }\end{array}$ \\
\hline 12 & Puncak 12 & 19,815 & 255 & $\mathrm{C}_{16} \mathrm{H}_{33} \mathrm{NO}$ & Hexadecanamide \\
\hline 13 & Puncak 13 & 21,421 & 281 & $\mathrm{C}_{18} \mathrm{H}_{35} \mathrm{NO}$ & Octadecenamide, \\
\hline 14 & Puncak 14 & 21,629 & 283 & $\mathrm{C}_{18} \mathrm{H}_{37} \mathrm{NO}$ & Octadecanamide \\
\hline 15 & Puncak 15 & 22,883 & 278 & $\mathrm{C}_{16} \mathrm{H}_{22} \mathrm{O}_{4}$ & $\begin{array}{l}\text { 1,2-Benzenedicarboxylic } \\
\text { acid,mono(2-ethylhexyl) ester }\end{array}$ \\
\hline
\end{tabular}

\section{Simpulan}

Berdasarkan hasil analisis dengan mengguanakan KG-SM ditemukan 11 senyawa dalam ekstrak methanol kulit batang ampupu yang berpotensi sebagai fungisida nabati yaitu Ethylbenzene, o-Xylene, ALPHA.-PINENE,DELTA.3Carene, Azulene(CAS)Cyclopentacycloheptene, Tetradecane(CAS)nTetradecane, 2,6-Diisopropylnaphthalene, 7,9-Di-tert-butyl-1oxaspiro(4,5)deca-6,9-dien, Hexadecanamide, 9-Octadecenamide, (Z)(CAS)OLEOAMIDE, 1,2-Benzenedicarboxylicacid,mono(2-ethylhexyl).

\section{Pustaka}

Ardiansyah. 2005. Antimikroba dari Tumbuhan (bagian kedua) Available from: http://www.berita iptek.com. (diakses pada tanggal 6 oktober 2015)

Astiti, N. P. A. And Suprapta, D. N. 2012. Antifungal activity of teak (Tectona grandis L.f) leat extract against Athrinium phaeospermum (Corda) M. B. Ellis, the cause of wooddecay on Albizia falcataria (L.) Fosberg. Journal of ISSAAS 18(1):62-69

Baco, D. dan J. Tandiabang. 1988. Hama Jagung dan Pengendaliannya. Badan Litbang Pertanian. p. $185-204$.

Badan Pusat Statistik. 2014. Laporan Data Sosial Ekonomi: direktorat statistik Tanaman Pangan, Hortikultura dan Perkebunan. Katalog BPS (50). p. 82 86. ISSN: 2087-930X.

Goldman, L.R. 2008. Encyclopedia of Public Health : Fungicides.

Harbone, J. B. 1996. Metode Fitokimia : Penuntun Casra Moderen Menganalisis Tumbuhan, Terbitan Kedua, ITB : Bandung

Pakki, Syahrir dan Syahrir Ma'sud, 2005. Inventarisasi Dan Identifikasi Patogen Cendawan Yang Menginfeksi Benih Jagung. Balai Penelitian Tanaman Serealia. Prosiding Seminar Ilmiah Dan Pertemuan Tahunan Pei Dan Pfi Xvi Komda Sul-Sel 
Pakki, S. 2006. Patogen Tular Benih Fusarium sp. dan Aspergillus sp. pada jagung serta pengendaliannya. Prosiding seminar nasional jagung. Balitsereal Maros. p. 588-598.

Pasaribu, T, B., Tangendjaja and Wina, E.1995.Limbah Tanaman dan Produk SampingIndustri Jagung untuk Pakan. Prosiding SeminarNasional Sains dan Teknologi Peternakan. p. 427-455.

Suprapta, D. N. 2014. Pestisida Nabati: Potensi dan Prospek Pengembangan. Penerbit Pelawa Sari. Denpasar 